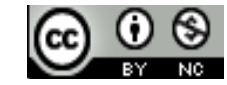

Jurnal Bimbingan Konseling Indonesia is licensed under A Creative Commons Attribution-Non Commercial 4.0 International License.

\title{
KELAYAKAN PAKET KONSELING KELOMPOK BERBASIS RASIONAL-EMOTIF-PERILAKU UNTUK MEREDUKSI BURNOUT SISWA SMA
}

\author{
Ikke Yuliani Dhian Puspitarini $^{1)}$, Rosalia Dewi Nawantara ${ }^{2)}$ \\ 1) Program Studi Bimbingan dan Konseling, Universitas Nusantara PGRI Kediri, Indonesia \\ E-mail: ikkeydp@unpkediri.ac.id \\ 2) Program Studi Bimbingan dan Konseling, Universitas Nusantara PGRI Kediri, Indonesia \\ E-mail: rosaliadewi@unpkediri.ac.id
}

\begin{abstract}
Abstrak. Pendekatan Rational-Emotif-Behavior Therapy (REBT) dapat dirujuk oleh Guru BK sebagai pendekatan yang efektif untuk mengatasi berbagai permasalahan. Penerapan sistem full day school dapat berdampak terhadap psikologi siswa, salah satunya yaitu mengalami kejenuhan belajar (burnout) karena jangka waktu kegiatan belajar yang lama di sekolah. Peneliti bertujuan untuk mengembangkan Paket Konseling Kelompok Berbasis Rasional-Emotif-Perilaku (REP) untuk mereduksi burnout siswa Sekolah Menengah Atas (SMA). Metode peneltian yang digunakan adalah research and development. Sedangkan teknik pengumpulan data dengan skala akseptabilitas yang dikembangkan berdasarkan kritreria keberterimaan. Skala akseptabilitas digunakan untuk memperoleh penilaian dari 2 orang uji ahli BK, 2 orang orang uji media, 2 orang calon pengguan guru BK dan 5 orang calon pengguna dari siswa kelas XI SMAN 2 Nganjuk. Teknik analisis data menggunakan rumus perhitungan rata-rata. Hasil penelitian menunjukkan Paket Konseling Kelompok Berbasis REP untuk mereduksi burnout siswa SMA layak untuk digunakan dan dapat diterima sebagai panduan untuk Guru BK dan siswa, dengan hasil perhitungan rata-rata sebesar $86 \%$ yang berada pada rentang kategori sangat baik. Adapun hasil penilaian uji ahli BK sebesar 92\% dengan kategori sangat baik, penilaian uji ahli media sebesar 93\% dengan kategori sangat baik, uji calon pengguna guru BK sebesar 75\% menunjukkan kategori baik, serta uji calon pengguna siswa sebesar $84 \%$ dengan kategori sangat baik.
\end{abstract}

Kata Kunci: Paket Konseling Kelompok; Rasional-Emotif-Perilaku; Burnout

\section{PENDAHULUAN}

Profesionalisme layanan konseling seyogyanya terus dilakukan pihak-pihak yang terlibat secara langsung dengan pengembangan bidang pekerjaan dan mengacu pada kriteria pekerjaan profesional (Latipun, 2015). Selain itu, Guru BK yang memiliki pandangan dunia konseli dengan berbagai perspektif, sehingga dapat lebih berempati, berpikir terbuka, dan mempunyai kesadaran diri untul selalu memberikan perubahan yang berarti demi meningkatkan profesionalismenya (Arofah, Nawantara, \& Puspitasari, 2018).

Melaksanakan praktik konseling secara individual maupun kelompok yang sesuai dengan tahapan pendekatan yang tepat, merupakan salah satu wujud profesionalisme guru BK. Terdapat berbagai pendekatan atau teori konseling yang dapat diterapkan dalam konseling, salah satunya yaitu Rational-Emotif-Behavior Therapy (REBT) yang dipelopori oleh Albert Ellis pada tahun 1962. REBT lebih mengarahkan individu pada cara mengubah keyakinan irasional menjadi pikiran 
rasional supaya perasaan dan perilaku individu menjadi baik dan lebih fungsional (Hutchinson \& Chapman, 2005). Ellis (Corey, 2009) percaya bahwa manusia mempunyai kesediaan untuk berpikir, dan mampu melatih dirinya untuk mengganti atau menghilangkan pikiran-pikiran yang menyabotase diri. Selain itu, REBT juga sangat mungkin diadaptasikan dengan berbagai karakteristik konseli dan mengatasi beragam masalahnya.

Albert Ellis (Corey, 2009) mendeskripsikan konseling Rasional-Emotif-Perilaku (REP) model konseling yang mengajarkan konseli untuk mengarahkan atau menerapkan keyakinan atau pikiran pribadi yang rasional dengan mengubah pikiran yang irasional dengan menggunakan prinsip-prinsip Rational-Emotif-Behavior Therapy (REBT). Lebih lanjut Bond dan Dreyden (Darminto, 2007) mengemukakan bahwa dalam konseling REP, Ellis mengakui kognisi, emosi dan perilaku saling berinteraksi satu sama lain.

Permasalahan-permasalahan yang dialami individu diidentifikasi oleh Ellis dalam teori kepribadian yang dikenal dengan teori A-B-C. Ellis (Corey, 2009) menjelaskan teori A-B-C seperti berikut, A (Activating Event) merupakan keberadaan suatu fakta, peristiwa, tingkah laku atau sikap seseorang, B (Belief) merupakan keyakinan individu tentang A yang menjadi penyebab $\mathrm{C}$, dan $\mathrm{C}$ (Consequence) merupakan konsekuensi atau reaksi emosional seseorang yang dapat layak maupun tidak layak. Seorang terapis harus melawan D (Disputing Intervention) keyakinan-keyakinan irasional itu agar individu dapat menikmati dampak-dampak E (Effective New Philosophy) psikologis positif dari keyakinan-keyakinan yang rasional sehingga dapat menemukan perasaan yang baru yang digambarkan dengan $\mathrm{F}$ (New Feeling).

Beragam permasalahan yang dialami siswa, juga membutuhkan bantuan bersifat kuratif dari guru BK. Masalah yang dapat diselesaikan dengan pendekatan REBT diantaranya, kesulitan-kesulitan kognisi, emosi dan perilaku yang berkaitan dengan distress psikologi dan psikopatologi, serta berbagai gangguan emosi dan tingkah laku seperti agresi, kecemasan, depresi, hiperaktif, kecanduan alkohol dan kegemukan khususnya pada kelompok/populasi anak-anak (Darminto, 2007). Pendekatan REBT dapat dirujuk oleh Guru BK sebagai pendekatan yang efektif untuk mengatasi berbagai permasalahan.

Sistem full day school yang diimplementasikan akhir-akhir ini berdampak positif, diantaranya guru berkesempatan mendidik karakter siswa dengan waktu yang lebih lama di sekolah dan waktu belajar di sekolah semakin intensif. Tetapi selain itu, full day school juga memilki efek negatif terhadap psikologi siswa. Siswa dapat mengalami kejenuhan belajar (burnout) karena jangka waktu kegiatan belajar di sekolah selama 8 jam setiap hari. Full day school dikhawatirkan bisa membuat siswa burnout, bahkan membuat siswa susah menangkap pelajaran karena mengharuskan siswa di sekolah mulai pukul 07.00 WIB sampai pukul 16.00 WIB untuk belajar (Yudi, 2018).

Siswa Sekolah Menengah Atas (SMA) berada pada tugas perkembangan remaja, seringkali mengalami berbagai konflik dan rentan untuk mengalami stress. Stress yang diidentikan dengan gangguan yang terjadi pada orang dewasa juga dapat dialami oleh remaja dan anak-anak. Remaja yang mempunyai kemampuan coping stress yang kurang baik akan menyebabkan rendahnya kontrol diri dan akhirnya menimbulkan tingkah laku maladaptif seperti bolos sekolah, tidak menerjakan tugas, malas belajar, dan acuh terhadap tata tertib sekolah (Skovholt, 2003). Stress yang berkepanjangan akan menyebabkan terjadinya burnout.

Burnout dapat terjadi siswa apabila kehilangan motivasi dan konsolidasi salah satu tingkat keterampilan tertentu sebelum siswa tersebut sampai pada tingkat keterampilan berikutnya (Puspitarini, 2017). Burnout juga dapat terjadi karena proses belajar siswa telah sampai pada batas kemampuan jasmaniahnya karena bosan (boring) dan letih (fatigue), kurangnya penghargaan dari sekolah dan banyaknya tugas belajar biasanya menjadi faktor penyebab burnout (Puspitarini, 2017). Kondisi tersebut dikuatkan oleh penelitian yang dilakukan oleh Stufflebeam (Stufflebeam, 1994) menunjukkan sebagian besar faktor pemicu burnout pada kegiatan akademik adalah karena 
rutinitas yang tidak banyak berubah dan cenderung monoton.

Burnout is a psychological term for the experience of long-term exhaustion and diminished interest (Chaplin, 1995). Pertama kali menjelaskan konsep kejenuhan belajar dan dikembangkan dalam salah satu penelitian dengan hasil temuan bahwasanya kecenderungan kejenuhan dengan segala faktor penyebabnya bukan hanya terjadi pada adegan pekerjaan saja, akan tetapi kejenuhan dapat terjadi pada kegiatan belajar (Cherniss, 1980). Kejenuhan belajar muncul dari adanya proses pengulangan belajar yang tidak mendatangkan prestasi atau hasil yang memuaskan sehingga membuat individu letih baik secara fisik maupun psikis.

Burnout terjadi sebagai respon terhadap tuntutan akademis yang banyak sehingga individu mengalami stress dan tidak mampu mengelola tuntutan tersebut. Burnout bisa menyebabkan tekanan mental dalam bentuk kecemasan (Suwanto \& Fitriyadi, 2019). Dinamika burnout dimulai dari adanya tuntutan akademis serta harapan dari masyarakat terhadap individu (Chaplin, 1995). Hal ini menunjukkan bahwa burnout diawali dengan munculnya stress akibat tuntutan baik diri, orang tua maupun masyarakat. Akibatnya, siswa mengalami keletihan emosional (emotional exhaution), sinis terhadap belajar (cynicism), dan menurunya rasa keyakinan akademis (reduce academic efficacy). Banyak faktor yang mempengaruhi terjadinya burnout seperti yang dikemukakan oleh Silvar (Silvar, 2001) yakni terdiri dari faktor personal seperti keyakinan diri dan motivasi. Fakor lingkungan belajar turut memberikan pengaruh besar seperti hubungan baik dengan teman dan iklim belajar yang kondusif akan mencegah timbulnya burnout.

Burnout dapat dialami siswa karena mengalami stress berkepanjangan dan tidak dikelola dengan baik. Stress merupakan reaksi emosional sebagai salah satu hasil dari gangguan kognitif yang cukup berat jika berhadapan dengan stressor yang serius, sehingga berpengaruh pada konsentrasi dan mengorganisasikan pikiran secara logis (Karabiyik, 2009). Artinya sumber dari burnout terjadi akibat distorsi kognitif terhadap segala tekanan baik dari dalam diri atau lingkungan, yang dapat berpengaruh terhadap keseimbangan psikis maupun fisik.

Dengan demikian, burnout merupakan masalah yang harus segera mendapatkan intervensi yang tepat. Salah satu upaya intervensi bersifat kuratif, dengan pendekatan konseling berbasis REP dengan seting kelompok, yang selanjutnya disebut dengan konseling kelompok REP. Konseling kelompok adalah upaya bantuan kepada individu dengan menggunakan dinamika kelompok, bersifat pencegahan dan pengembangan kemampuan pribadi sebagai pemecahan masalah secara kelompok dari seorang konselor kepada konseli (Atkinson, 2010). Konselor atau guru BK dapat menerapkan konseling kelompok dengan mengolaborasikan berbagai pendekatan, strategi atau teknik konseling yang bertujuan untuk membantu siswa menyelesaikan masalah (Lubis, 2016).

Alasan menggunakan konseling kelompok REP yaitu dalam tahapan-tahapan kegiatannya, anggota kelompok yang mengalami burnout diarahkan konselor melalui dinamika kelompok untuk mengidentifikasi permasalahan burnout akibat dari keyakinan atau pikiran irasional keproses berpikir secara rasional. Selain itu masing-masing anggota kelompok saling memberikan penguatan kepada anggota kelompok lainnya. Konselor selaku pemimpin kelompok menggunakan berbagai metode-metode kognitif secara aktif seperti disputing (memperdebatkan), teaching (mengajarkan) dan persuading (mengajak) kepada anggota kelompok untuk mengganti keyakinan irasional ke sistem rasional (Trifena, Istirahayu, \& Fitriyadi, 2020).

Adapun tujuan umum konseling kelompok REP adalah membantu konseli untuk mengidentifikasi masalah emosi dan perilaku serta mengatasi masalah-masalah tersebut. Proses konseling kelompok REP terdiri dari tiga tahapan utama dan dalam setiap tahapan konselor dapat menggunakan berbagai teknik yang disesuaikan dengan permasalahan dan karakteristik konseli (Corey, 2007). Tiga tahapan utama konseling REP; (a) beginning stage yang terdiri dari membangun aliasi terapeutik yang produktif antara konselor dan konseli, kemudian mengajarkan metode $\mathrm{ABC}$ 
(activating event, belief, conscequence) guna memahami adanya pikiran irasional, dan mengatasi keraguan konseli guna membangun kepercayaan konseli terhadap keefektifan konseling REP; (b) middle stage, diantaranya mempertimbangkan untuk mengubah fokus masalah untuk membangun kemampuan coping terhadap permasalahan utama konseli, kemudian mengidentifikasi dan memodifikasi keyakinan irasional inti yang merupakan akar dari permasalahan konseli, setelah itu mendorong konseli untuk terlibat dalam tugastugas yang relevan untuk memperkuat pendirian terkait keyakinan rasionalnya supaya dapat mencapai tujuan tersebut dan dapat menggunakan beragam teknik konseling REP (Corey, 2007). Lanjutan tahapan kedua konseling REP yaitu mengatasi hambatan terhadap perubahan yang biasanya diwakili oleh keadaan yang disebut 'disonansi kognitif-emosional' yakni keadaan dimana konseli merasa 'asing' seiring mereka berusaha untuk memperkuat keyakinan rasional, kemudian mendorong konseli untuk memelihara dan meningkatkan pencapaian tujuan, serta memotivasi konseli untuk mencapai konselor bagi dirinya sendiri dengan mempertanyakan keyakinan irasional dan mengembangkan alternatif keyakinan rasional hingga mempertahankan; (c) ending stage, dimulai ketika konseli dianggap telah membuat kemajuan signifikan menuju penyelesaian masalah utama dengan menggunakan metode pemecahan masalah REP.

TABEL I

NAMA TABEL

\begin{tabular}{llll}
\hline $\begin{array}{l}\text { Uku } \\
\text { ran } \\
\text { Font }\end{array}$ & \multicolumn{2}{c}{ Tampilan (dalam Time New Roman) } \\
\cline { 2 - 3 } & Biasa & \multicolumn{1}{c}{$\begin{array}{c}\text { Cetak } \\
\text { Tebal }\end{array}$} & Cetak Miring \\
\hline 8 & $\begin{array}{l}\text { Keterangan tabel } \\
\text { (dalam Small Caps), } \\
\text { keterangan gambar, }\end{array}$ & Kutipan (parsial) \\
& $\begin{array}{l}\text { kutipan } \\
\text { Alamat email penulis } \\
\text { (dalam Courier), }\end{array}$ & $\begin{array}{l}\text { Bagian } \\
\text { abstrak }\end{array}$ & $\begin{array}{l}\text { Sub judul abstrak } \\
\text { (cetak tebal) }\end{array}$ \\
& $\begin{array}{l}\text { Sel tabel } \\
\text { Sub judul level-1 }\end{array}$ & & $\begin{array}{l}\text { Sub judul level-2, } \\
\text { Sub judul level-3, } \\
\text { afiliasi penulis }\end{array}$ \\
& $\begin{array}{l}\text { (dalam Small Caps), } \\
\text { paragraf }\end{array}$ & & \\
12 & $\begin{array}{l}\text { Nama penulis } \\
\text { Judul Artikel }\end{array}$ & & \\
\hline
\end{tabular}

II. METODE
Pengembangan paket konseling rasional-emotifperilaku (REP) dalam penelitian ini menggunakan jenis penelitian research and development (penelitian dan pengembangan) dengan sepuluh langkah (Dryden \& Neenan, 2004). Adapun langkah-langkah tersebut: a) pengumpulan data; b) perencanaan; c) pengembangan draf produk; d) uji coba lapangan; e) revisi produk awal; f) uji coba lapangan; g) revisi produk hasil uji lapangan; h) uji pelaksanaan lapangan; i) revisi produk akhir; j) diseminasi dan implementasi. Kesepuluh langkah tersebut dimodifikasi oleh peneliti dengan tiga tahapan yang disesuaikan dengan kebutuhan penelitian. Pengembangan Paket Konseling Kelompok Berbasis REP dilaksanakan sampai pada tahap uji calon pengguna. Tiga tahap pengembangan tersebut terdapat pada gambar 1 .

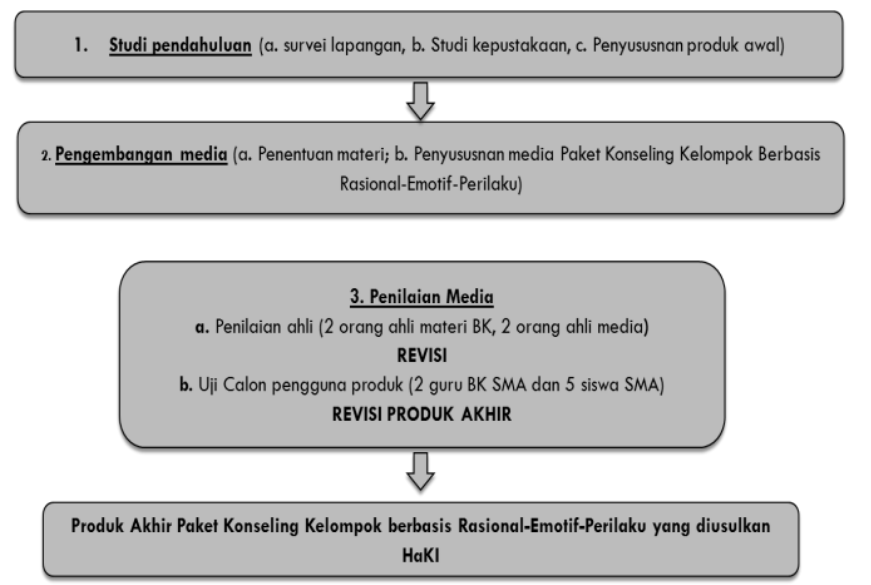

Gambar 1 Tahapan penelitian pengembangan paket konseling kelompok berbasis REP

Adapun teknik pengumpulan data berupa skala akseptabilitas yang dikembangkan berdasarkan kritreria keberterimaan oleh The Joint Committe On Standards For Educational Evaluation (Borg \& Gall, 1983) yang mencakup aspek kegunaan, kelayakan, ketepan dan kemungkinan dikerjakan. Terdapat rating berupa skala 1-4 pada setiap pernyataan pada skala akseptabilitas, diantaranya: 1 = tidak jelas/ tidak tepat/ tidak praktis/ tidak relevan/ tidak perlu/ tidak penting; 2 = kurang jelas/ kurang tepat/ kurang praktis/ kurang relevan/ kurang perlu/ kurang penting; 3 = jelas/ tepat/ praktis/ relevan/ perlu/ penting; $4=$ sangat jelas/ sangat tepat/ sangat praktis/ sangat relevan/ sangat perlu/ sangat penting. Kemudian ditentukan empat 
kriteria untuk interpretasi hasil penelitian, yaitu: 1) sangat baik dengan rentang $76 \%$ - 100\%; 2) baik dengan rentang $51 \%-75 \%$; 3) kurang baik dengan rentang 26\% - 50\%; dan 4) tidak baik dengan rentang $0 \%$ - 25\%. Pengujian untuk memperoleh hasil penilaian ahli dan pengguna menggunakan rumus perhitungan rata-rata pada gambar 2 (Sudjana, 2011).

$$
\frac{\text { skor hasil observasi }}{\text { skor maksimal }} \times 100 \%
$$

Gambar 2 Rumus perhitungan rata-rata

\section{HASIL DAN PEMBAHASAN}

Hasil dari penelitian ini adalah produk berupa Paket Konseling Kelompok Berbasis REP (untuk Guru BK) dan Paket Konseling Kelompok Berbasis REP (untuk Konseli). Paket tersebut telah dinilai oleh dua orang uji ahli BK, dua orang ahli media, dan dua orang guru BK serta lima siswa kelas XI SMAN 2 Nganjuk sebagai calon pengguna. Adapun kelayakan Paket Konseling Kelompok Berbasis REP berdasarkan dari hasil uji keberterimaan para ahli dan calon pengguna ditentukan dari rata-rata sebesar $86 \%$ yang berada pada rentang kategori sangat baik. Hal tersebut menunjukkan bahwa Paket Konseling Kelompok Berbasis REP memenuhi kriteria akseptabilitas ahli dan pengguna. Sehingga dapat digunakan sebagai panduan/petunjuk bagi Guru BK untuk mereduksi burnout yang dialami oleh konseli/anggota kelompok.

TABEL II

HASIL UJI KEBERTERIMAAN AHLI DAN PENGGUNA

\begin{tabular}{cll}
\hline \multicolumn{1}{c}{ Penguji } & \multicolumn{1}{c}{ Hasil } & \multicolumn{1}{c}{ Interprestasi } \\
\hline Ahli BK & Hasil penghitungan uji ahli BK & Dari hasil analisis \\
& menunjukkan hasil sebesar 92\%. & penilaian, paket \\
& Paket Konseling Kelompok & yang dikembangkan \\
berbasis REP telah direvisi sesuai & masuk dalam \\
& saran ahli, yaitu paket ditambah & kategori sangat baik \\
& dengan pengantar, daftar isi, & sehingga memenuhi \\
& konsep konseling kelompok, & keberterimaan ahli \\
& kompetensi konselor, kerangka & BK setelah melalui \\
& kerja, tujuan, dan & proses revisi \\
& lampiran/lembar kerja yang & \\
disesuaikan kebutuhan. & \\
Ahli Media & Hasil penghitungan uji ahli media & Dari hasil analisis \\
& sebesar 93\%. Paket Konseling & penilaian, paket \\
& Kelompok berbasis REP telah & yang dikembangkan \\
& direvisi sesuai saran ahli, yaitu & masuk dalam \\
& paket sudah didaftarkan pada & kategori sangat baik \\
& HAKI. Selain itu ada masukan & sehingga memenuhi \\
& mengenai desain paket termasuk & keberterimaan ahli
\end{tabular}

"header" dan "footer" yang lebih baik diredesain ulang. Hasil penghitungan uji calon pengguna Guru BK sebesar 75\%. Paket Konseling Kelompok berbasis REP telah direvisi sesuai saran calon pengguna, yaitu ice breaking dapat dikemas dengan lebih meriah, Video dalam paket sudah bagus, akan tetapi mungkin bisa ditambahkan video lain agar lebih kuat. Selain itu, uji penelitian sudah baik perlu dipertahankan untuk tindakan berikutnya.

Calon Hasil penghitungan uji calon Pengguna pengguna siswa sebesar $84 \%$. Siswa Paket Konseling Kelompok berbasis REP telah direvisi sesuai saran calon pengguna, yaitu ditambahkan gambar yang lebih banyak agar paket lebih menarik, gambar pada cover belum mencerminkan siswa SMA, dan Desain paket bisa diperbaiki agar lebih menarik. Kata yang "typo" bisa diperbaiki pada beberapa halaman.

\section{PEMBAHASAN}

Berlandaskan penilaian uji ahli dan calon pengguna, diketahui bahwa Paket Konseling Kelompok Berbasis REP dapat diterima secara teoritis dan praktis. Hal tersebut dapat diamati berdasarkan hasil penilaian uji ahli BK dan uji ahli media dengan kategori sangat baik, dan uji calon pengguna guru BK menunjukkan kategori baik serta uji calon pengguna siswa dengan kategori sangat baik. Selain hasil kelayakan bersumber dari data angka, terdapat pula deskripsi saran dari uji ahli dan pengguna. Rincian saran tersebut dijadikan landasan perbaikan Paket Konseling Kelompok Berbasis REP agar semakin berkualitas.

Paket Konseling Kelompok Berbasis REP (untuk Guru BK) digunakan oleh konselor/guru BK pada saat pelaksanaan treatment agar lebih terstruktur dan sistematis dalam membantu siswa mereduksi burnout. Selain berisi materi terkait dengan burnout, paket konseling juga dilengkapi rincian kegiatan dan lembar refleksi kegiatan. Paket konseling kelompok ini mengacu pada pendekatan Rational Emotif - Behavior Therapy (REBT) yang terdiri dari tiga tahapan, yaitu: begining stage (tahap awal); middle stage (tahap pertengahan; ending stage (tahap akhir) dan disusun dalam lima sesi konseling. 
Sedangkan Paket Konseling Kelompok Berbasis REP (untuk Konseli) digunakan oleh konseli pada saat pelaksanaan treatment sebagai skala deskriptif untuk mengetahui usaha atau keberhasilan konseli dalam mereduksi burnout. Paket ini berisi materi terkait dengan burnout dan dilengkapi juga dengan tugas/bahan latihan yang menekankan pada aktifitas mandiri konseli. Dengan paket ini, diharapkan dapat membantu aktifitas konseli agar terlibat aktif dalam kegiatan konseling kelompok. Selain itu, melalui konseling kelompok REP, konseli menyadari pikiran irasional dapat merugikan mereka sendiri, dan dengan kesadaran tersebut mereka dapat memperbaiki serta merubah menjadi pikiran rasional, mengelola emosi dan tingkah laku secara positif (Puspitarini, 2016).

\section{KESIMPULAN}

Berdasarkan hasil uji ahli dan uji calon pengguna, didapatkan simpulan bahwa produk Paket Konseling Kelompok Berbasis REP untuk mereduksi burnout siswa SMA layak untuk digunakan dan dapat diterima sebagai panduan untuk Guru BK sebagai ketua kelompok dan siswa sebagai anggota kelompok. Aspek penilaian produk meliputi aspek ketepatan, kesesuaian, kejelasan dan kemenarikan. Evaluasi dari ahli dan calon pengguna menjadi dasar untuk merevisi produk, sehingga dihasilkan Paket Konseling Kelompok Berbasis REP yang sangat baik serta efektif secara teoritis maupun praktis.

\section{DAFTAR PUSTAKA}

Arofah, L., Nawantara, R. D., \& Puspitasari, A. D. (2018). Pengembangan Panduan Solution Focused Brief Counseling Untuk Guru BK Sekolah Menengah Pertama Negeri (SMPN) 1 Kota Kediri. Jurnal Bikotetik, 2(1), 100-104.

Atkinson, R., \& Etal. (2010). Pengantar Psikologi, Jilid Dua. Tangerang: Interkasara Publisher.

Borg, W. R., \& Gall, M. D. (1983). Educational Research: an Introduction. New York: Longman.

Chaplin, J. (1995). Kamus Istilah Psikologi. Jakarta: Penerbit Rajawali Press.

Cherniss. (1980). Staff Burnout Job Stress in the Human Services. London: Sage Publications.

Corey, G. (2007). Teori dan Praktek Konseling dan Psikoterapi (Penerjemah: E-Koeswara). Bandung: PT
Rafika Aditama.

Corey, G. (2009). Theory and Practice of Counseling and Psychotherapy. USA: Thomson Higher Education.

Darminto, E. (2007). Teori-Teori Konseling. Surabaya: Unesa University Press.

Dryden, W., \& Neenan, M. (2004). Rational Emotive Behavioral Counselling in Action (3rd. ed.). London: SAGE Publication Ltd.

Hutchinson, G., \& Chapman, P. (2005). Logotherapy Enhanced REBT: An Integration of Discovery and Reason. Journal of Contemporary Psychotherapy, 35(2), 145-155.

Karabiyik, L., \& Etal. (2009). Determining The Factors That Affect Burnout Among Academicians. Journal of Ankara University, 63(2), 92-114.

Latipun. (2015). Psikologi Konseling. Malang: UMM Press.

Lubis, L. (2016). Konseling Kelompok. Jakarta: Kencana.

Puspitarini, I. (2016). Penerapan Konseling Kelompok Rasional-Emotif-Perilaku Untuk Membantu Siswa Mengatasi Distress. Jurnal Nusantara of Research, 3(2), 2016.

Puspitarini, I. Y. D. (2017). Teknik Self Instruction (Solusi Bagi Remaja Untuk Mereduksi Distress. Prosiiding Seminar Nasional.

Silvar, B. (2001). The Syndrome of Burnout, Self-Image, and Anxiety with Grammar School Students. Journal of Psychology, 10(2), 21-32.

Skovholt. (2003). Student Learning Burnout Studied", Families in Society. The Journal of Contemporary Human Service.

Stufflebeam, D. L. (1994). Introduction: Recommendations for Improving Evaluating in US Public Schools. Studies in Education Evaluation, 20(1), 3-21.

Sudjana, N. (2011). Penilaian Hasil Proses Belajar Mengajar. . Bandung: PT. Remaja Rosdakarya Offset.

Suwanto, I., \& Fitriyadi, S. (2019). Burnout Guru BK di Kota Singkawang. Counsellia: Jurnal Bimbingan Dan Konseling, 9(2), 127-136.

Trifena, R., Istirahayu, I., \& Fitriyadi, S. (2020). Layanan Konseling Kelompok Menggunakan Teknik SelfManagement Untuk Mengurangi Perilaku Merokok Siswa di SMP Negeri 1 Teriak. Jurnal Bimbingan Konseling Indonesia, 5(2), 46-49.

Yudi. (2018). lebihan dan Kekurangan Full Day School. Retrieved from https://www.inspiradata.com/kelebihandan-kekurangan-full-day-school/ 